International Journal of

Environmental Research and

Public Health

ISSN 1660-4601

www.mdpi.com/journal/ijerph

Article

\title{
Placental Transfer of Persistent Organic Pollutants: A Preliminary Study on Mother-Newborn Pairs
}

\author{
Maria Grazia Porpora ${ }^{1, *}$, Renato Lucchini ${ }^{2}$, Annalisa Abballe ${ }^{3}$, Anna Maria Ingelido ${ }^{3}$, \\ Silvia Valentini ${ }^{3}$, Eliana Fuggetta ${ }^{1}$, Veronica Cardi ${ }^{1}$, Adele Ticino ${ }^{1}$, Valentina Marra ${ }^{3}$, \\ Anna Rita Fulgenzi ${ }^{3}$ and Elena De Felip ${ }^{3}$
}

1 Department of Gynaecology, Obstetrics and Urology, "Sapienza" University of Rome, Policlinico Umberto I, Viale del Policlinico 155, 00161 Rome, Italy;

E-Mails: mariagrazia.porpora@uniroma1.it (M.G.P.); eliana.fuggetta@gmail.com (E.F.); veronica.cardi@gmail.com (V.C.); adele.ticino@yahoo.com (A.T.)

2 Perinatology and Childcare, "Sapienza" University Policlinico Umberto I, Viale del Policlinico 155, 00161 Rome, Italy; E-Mail: renato.lucchini@uniroma1.it

3 Toxicological Chemistry Unit, Department of the Environment and Primary Prevention, Istituto Superiore di Sanità, Viale Regina Elena 299, 00161 Rome, Italy;

E-Mails: annalisa.abballe@iss.it (A.A.); annamaria.ingelido@iss.it (A.M.I.); silvia.valentini@iss.it (S.V.); valentina.marra@iss.it (V.M.); annarita.fulgenzi@iss.it (A.R.F.); elena.defelip@iss.it (E.D.F.)

* Author to whom correspondence should be addressed; E-Mail: annalisa.abballe@iss.it; Tel.: +39-06-4990-2378; Fax: +39-06-4990-2836.

Received: 14 December 2012; in revised form: 1 February 2013 / Accepted: 4 February 2013 / Published: 7 February 2013

\begin{abstract}
The aim of this study was to characterize the placental transfer of some environmental pollutants, and to explore the possibility of quantitatively predicting in utero exposure to these contaminants from concentrations assessed in maternal blood. Levels of toxic substances such as pesticides ( $p, p^{\prime}-\mathrm{DDE}, \beta-\mathrm{HCH}$, and $\mathrm{HCB}$ ), polychlorinated biphenyls (PCBs), perfluorooctane sulfonate (PFOS), and perfluorooctanoic acid (PFOA) were determined in serum samples of 38 pregnant women living in Rome and in samples of cord blood from their respective newborns. The study was carried out in the years 2008-2009. PCB mean concentrations in maternal serum and cord serum ranged from 0.058 to 0.30 , and from 0.018 to $0.064 \mathrm{ng} / \mathrm{g} \cdot \mathrm{fw}$ respectively. Arithmetic means of PFOS and PFOA concentrations in mothers and newborns were 3.2 and $1.4 \mathrm{ng} / \mathrm{g} \cdot \mathrm{fw}$, and 2.9 and
\end{abstract}


$1.6 \mathrm{ng} / \mathrm{g} \cdot \mathrm{fw}$. A strong correlation was observed between concentrations in the maternal and the foetal compartment for PFOS (Spearman $r=0.74, p<0.001$ ), PFOA (Spearman $\mathrm{r}=0.70, \mathrm{p}<0.001$ ), PCB 153 (Spearman $\mathrm{r}=0.60, \mathrm{p}<0.001)$, HCB (Spearman $\mathrm{r}=0.68$, $\mathrm{p}<0.001$ ), PCB 180 (Spearman $\mathrm{r}=0.55, \mathrm{p}=0.0012$ ), and $p, p^{\prime}$-DDE (Spearman $\mathrm{r}=0.53$, $\mathrm{p}=0.0099)$. A weak correlation $(\mathrm{p}<0.1)$ was observed for PCBs 118 and 138 .

Keywords: $p$, $p$ '-DDE; $\beta$-HCH; HCB; polychlorinated biphenyls (PCBs); perfluorooctane sulfonate (PFOS); perfluorooctanoic acid (PFOA); in utero exposure; placental transfer

\section{Introduction}

Persistent organic pollutants (POPs) are a group of toxic chemicals widely distributed in the environment which includes polychlorinated dibenzodioxins (PCDDs), polychlorinated dibenzofurans (PCDFs), polychlorinated biphenyls (PCBs), organochlorinated pesticides and perfluorinated organic compounds (PFCs). These chemicals have been recognised as a threat to the environment and human health because of their high chemico-physical stability, long environmental and biological persistence, and a wide range of toxic effects. A number of studies suggest that exposure to PCBs and organochlorinated pesticides may lead to increased cancer risk [1-5], nervous system damage [6,7], reproductive disorders [8-11], and immune system disruption [12,13] .

As to the two most abundant members of the perfluorinated compound family, perfluorooctane sulfonate (PFOS) and perfluorooctanoic acid (PFOA), the main effects observed in animal models are hepatotoxicity, developmental toxicity, immunotoxicity and hormonal effects. Animal studies also suggest that at relatively high doses PFOS and PFOA may be carcinogenic [14-19].

As a consequence of POP toxic effects on human health, a number of regulatory measures have been undertaken at an international level to eliminate or reduce their release into the environment and human exposure. Human exposure monitoring over time allows one to evaluate if measures undertaken are effective in reducing the release of POPs into the environment. Biomonitoring is recognised as the most effective tool to characterize exposure to POPs since it provides the direct measurement of the internal dose of a chemical resulting from all sources and pathways, which represents the most appropriate dose-metric for risk assessment [20].

Exposure of infants and children is one of the major points of concern associated to POPs. In fact, many epidemiological studies suggest that prenatal and postnatal exposure to organochlorinated compounds is linked to a number of adverse effects in children such as neurodevelopmental delays and disorders [21-25]. In addition, effects that may become evident later in life [13] are also associated with exposure that occurs in this stage of life. With regard to PFCs, prenatal exposure to PFOS and PFOA has been associated to decreased fecundity and reduced sperm counts, motility and morphology [26,27], although conflicting results have been reported by different studies [17,26,28,29]. Elevated exposures to PFCs in children aged 5 and 7 years have been associated with a decreased immune response to childhood vaccines, which might reflect a more general immune system deficit [30]. 
While perinatal exposure to POPs through breastfeeding may be quite well characterized through the analysis of breast milk and the application of appropriate toxicokinetic models, the characterization of in utero exposure through the analysis of POPs in cord serum is still inadequate. In fact, practical and ethical problems often hamper the availability of cord serum samples and/or of the sample volume needed for the analysis of these lipophilic compounds in a matrix, such as cord blood, characterized by a low fat content.

The main aim of the present human biomonitoring study was to assess if a quantitative relationship may be established to characterize the placental transfer of a group of POPs present in greatest abundance in human tissues, and therefore to predict in utero exposure to these contaminants from levels assessed in maternal blood.

The most abundant PCB congeners (the so-called "indicator" PCBs 28, 52, 101, 138, 153, and 180 plus PCBs 118 and 156), the organochlorinated pesticides $p, p^{\prime}$-dichlorodiphenyldichloroethylene ( $p, p^{\prime}$-DDE), $\beta$-hexachlorocyclohexane $(\beta-\mathrm{HCH})$ and hexachlorobenzene $(\mathrm{HCB})$, and the two main members of the family of the perfluorinated compounds (PFOS and PFOA) were therefore analysed in matched mother-newborn pairs.

\section{Materials and Methods}

\subsection{Recruitment of Study Participants, Sample Collection and Analysis}

Women subject enrolment was carried out between May 2008 and May 2009 at the Department of Gynaecology-Obstetrics and Urology, Policlinico Umberto I, University of Rome "Sapienza". The study, approved by the Local Research Ethic committee, involved 38 mother-child pairs.

A sample of about $30 \mathrm{~mL}$ of blood was withdrawn from each woman at the time of hospitalization or the next hours after delivery. Cord blood samples were taken during the delivery, either vaginal or by caesarean section, between childbirth and placental expulsion. All women gave informed consent for themselves and for their infants before participating in the study.

Blood samples were centrifuged to obtain serum. Only a few milliliters of serum were obtained from the umbilical cord blood, due to the high hematocrit (average value of 44-62\%) of fetal blood [31]. Serum samples were stored at $-20^{\circ} \mathrm{C}$ until time of analysis.

Birth weight of infants was measured within 1 hour from delivery with an electronic balance and recorded to the nearest gram. Birth crown-heel length and head circumference were measured within $1 \mathrm{~h}$ with a Harpenden neonatometer and an inelastic tape, respectively, and recorded to the nearest millimeter. Percentile was calculated using Italian Neonatal Anthropometric Charts [32]. Apgar score was evaluated by the attending neonatologist in the delivery room at one and five minutes after birth.

\subsection{Analysis}

\subsubsection{Organochlorinated Pesticides and PCBs}

An aliquot of about 4-12 mL of each maternal serum sample and about 3-5 mL of each cord serum were added with a mixture of ${ }^{13} \mathrm{C}$ labelled $\mathrm{PCBs}(28,52,101,118,138,153,156,180)$, and a mixture of ${ }^{13} \mathrm{C}$ labelled pesticides ( $p, p$ 'DDE, $\mathrm{HCB}, \beta-\mathrm{HCH}$ ), and allowed to rest overnight at $4{ }^{\circ} \mathrm{C}$. Formic acid/2-propanol (4/1, v/v, $15 \mathrm{~mL})$ were added to the samples, which were sonicated and extracted by 
manual shaking with $n$-hexane. After centrifugation, the organic phase was removed and collected. This extraction process was repeated two times. The $n$-hexane extracts were treated with concentrated sulphuric acid, separated by centrifugation and then concentrated and transferred into $1 \mathrm{~mL}$ autosampler vials. After addition of $1 \mu \mathrm{L}$ of tetradecane, extracts were concentrated to dryness, an isooctane solution of the injection standard $(200 \mu \mathrm{L})$ was added, and samples were quantified [33-35].

Instrumental analysis was carried out by ion trap mass spectrometry (Thermo Finnigan Polaris Q) coupled to high resolution gas chromatography used in the MS-MS mode. The isotope dilution technique was applied throughout. Recoveries ranged from $60-120 \%$.

Analytical reliability was warranted by the use of an in-house validated method [33]. The laboratory has considerable experience in the analysis of halogenated organic microcontaminants and periodically participates in interlaboratory comparison exercises and proficiency tests on the analysis of PCDDs, PCDFs, PCBs, organochlorinated pesticides, and brominated flame retardants in dietary, biological, and environmental matrices.

\subsubsection{PFOS and PFOA}

An aliquot of about $250 \mu \mathrm{L}$ of each serum sample was fortified with a mixture of ${ }^{13} \mathrm{C}$-labelled PFOS and PFOA and allowed to stand overnight at $4{ }^{\circ} \mathrm{C}$. Extraction was performed with acetonitrile by manual shaking in a centrifuge tube, followed by centrifugation at 3,500 revolutions per minute (rpm) for $10 \mathrm{~min}$. Acetonitrile aliquots were removed, collected in centrifuge tubes, carefully concentrated by a multiple samples evaporator system and transferred to an autosampler vial to undergo instrumental analysis [36]. Instrumental analysis was carried out by HPLC (Waters 2695 separations module) interfaced to a mass spectrometer (Waters Micromass Quattro micro API) operated in the electrospray negative mode. Data were acquired using multiple reaction monitoring (MRM). The isotope dilution technique was applied throughout. Recovery ranges of ${ }^{13} \mathrm{C}$-labelled internal standards were $70-110 \%$. Analysis of blanks and control samples was systematically carried out to check the analytical reliability. Limits of detection for PFOS and PFOA were $0.05 \mathrm{ng} / \mathrm{g} \cdot \mathrm{fw}$ and $0.1 \mathrm{ng} / \mathrm{g} \cdot \mathrm{fw}$, respectively [36].

\subsection{Statistical Analysis}

The Shapiro-Wilk test was used to test the normal distribution of data. The Spearman test was used to evaluate the correlation between concentrations of organochlorinated pesticides, PCBs and PFCs in maternal and cord serum and the correlation between concentrations of all the analytes. Linear regression analysis was used to investigate the transfer behaviour of all compounds. The Spearman test was also used to evaluate the correlation between levels of POPs in maternal and foetal serum and gestational age, Apgar scores and weight at birth. All statistical analyses were carried out using STATISTICA, version 8.0 (StatSoft, Inc., Tulsa, Oklahoma).

\section{Results}

A total of 38 Italian Caucasian women aged 26-45 years (mean age, 34.5 years) and their newborns were included in this study. In Table 1, the general characteristics of the women and their infants are 
reported. Out of the enrolled women, 23 women were at their first pregnancy. Mean gestational age was 39 weeks (range 35-42 weeks).

Table 1. General characteristics of the enrolled women and their newborns.

\begin{tabular}{ccccc}
\hline Characteristics of Women $(\boldsymbol{n}=\mathbf{3 8})$ & Min & Median & Mean & Max \\
\hline Age & 26.0 & 34.0 & 34.6 & 45.0 \\
Gestational age (weeks) & 35 & 39 & 39 & 42 \\
BMI pre pregnancy & 18.0 & 22.7 & 22.3 & 25.2 \\
Characteristics of newborns $(n=38)$ & & & & \\
Baby birth weight $(\mathrm{g})$ & 2,190 & 3,213 & 3,239 & 4,420 \\
Baby birth length $(\mathrm{cm})$ & 45.1 & 49.0 & 49.6 & 57.0 \\
Baby head circumference $(\mathrm{cm})$ & 31.0 & 34.5 & 34.1 & 36.0 \\
Apgar score (1 min) & 4.0 & 8.0 & 8.2 & 9.0 \\
Apgar score (5 min) & 7.0 & 9.0 & 9.4 & 10.0 \\
\hline
\end{tabular}

Sample volume was sufficient for the analysis of PFOS and PFOA in all samples, while only 32 out of the 38 samples had a volume sufficient for the analysis of the organochlorinated compounds. With regard to maternal serum samples, $24 \%$ had concentrations below the limit of quantification (LOQ) of $\beta$-HCH and PCB $118,16 \%$ of PCBs 180,138 and 153, and $<5 \%$ of HCB, $p$, p'-DDE, PFOS and PFOA. LOQ values ranged from 1 to $10 \mathrm{pg} / \mathrm{g} \cdot \mathrm{fw}$ for PCBs and organochlorinated pesticides and were of 0.1 and $0.5 \mathrm{ng} / \mathrm{g} \cdot \mathrm{fw}$ for PFOS and PFOA respectively.

With regard to cord serum, the percent of samples with concentrations below LOQs were $74 \%$ for $\beta-\mathrm{HCH}, 53 \%$ for PCB $118,47 \%$ for $\mathrm{HCB}, 39 \%$ for $p$, $p$ '-DDE, $29 \%$ for PCB 138 and PFOA, 26\% for PCB 153, 18\% for PCB 180, and 3\% for PFOS. Concentrations of PCBs 28, 52, 101, and 156 were always below their respective LOQs in cord blood samples.

Concentrations of $\beta-\mathrm{HCH}, \mathrm{HCB}, p, p$ '-DDE, and PCBs 118, 138, 153 and 180, PFOS and PFOA assessed in maternal and cord serum are shown in Table 2, summarized by arithmetic means, medians, minimum and maximum values, 25th and 75th percentiles. Values are expressed on a fresh weight basis since lipid content of cord serum samples could not be determined because the majority of cord samples were hemolyzed, this unabling the application of enzymatic methods currently used for lipid determination [37].

The pesticide found at the highest concentration in both maternal and cord serum samples was $p, p^{\prime}$-DDE. Mean concentrations of this pollutant in maternal serum and cord serum were 2.0 and $0.52 \mathrm{ng} / \mathrm{g} \cdot \mathrm{fw}$ respectively. Concentrations of $\mathrm{HCB}$ and $\beta-\mathrm{HCH}$ in maternal serum and cord serum were 0.31 and 0.13 in cord $\mathrm{ng} / \mathrm{g} \cdot \mathrm{fw}$, and $0.16 \mathrm{ng} / \mathrm{g} \cdot \mathrm{fw}$ and $0.047 \mathrm{ng} / \mathrm{g} \cdot \mathrm{fw}$ respectively.

As to the PCB congeners, a similar pattern in relative abundance was observed in the maternal and foetal compartments, with levels of PCB $153>$ PCB $180>$ PCB $138>$ PCB 118. PCB mean concentrations in maternal serum and cord serum were 0.30 and $0.064 \mathrm{ng} / \mathrm{g} \cdot \mathrm{fw}$ for PCB $153,0.14$ and $0.030 \mathrm{ng} / \mathrm{g} \cdot \mathrm{fw}$ for PCB 138, 0.22 and $0.043 \mathrm{ng} / \mathrm{g} \cdot \mathrm{fw}$ for PCB 180. Mean concentrations of the dioxin-like PCB 118 were 0.058 and $0.018 \mathrm{ng} / \mathrm{g} \cdot \mathrm{fw}$ in maternal and cord serum, respectively.

Arithmetic means of PFOS concentrations were 3.2 and $1.4 \mathrm{ng} / \mathrm{g} \cdot \mathrm{fw}$ in mothers and infants, respectively, while PFOA mean concentrations were 2.9 and $1.6 \mathrm{ng} / \mathrm{g} \cdot \mathrm{fw}$. 
Table 2. Serum concentrations (ng/g, fresh weight) of organochlorinated pesticides $(\beta-\mathrm{HCH}, \mathrm{HCB}$ and $\mathrm{DDE})$, four congeners of polychlorobiphenyls (PCBs) and perfluorinated compounds (PFCs) in maternal and cord samples. Values rounded off to two figures. Concentrations $<$ LOQ included in the analysis.

\begin{tabular}{|c|c|c|c|c|c|c|c|}
\hline Compounds & $\mathbf{N}$ & Min & $\mathbf{P}_{25}$ & Median & Mean & $\mathbf{P}_{75}$ & Max \\
\hline$\beta$ - $H C H$ Maternal serum & 32 & 0.0090 & 0.039 & 0.065 & 0.16 & 0.13 & 1.5 \\
\hline$\beta-H C H$ Cord serum & 32 & 0.0014 & 0.014 & 0.024 & 0.047 & 0.057 & 0.25 \\
\hline$H C B$ Maternal serum & 32 & 0.060 & 0.12 & 0.17 & 0.31 & 0.44 & 1.4 \\
\hline$H C B$ Cord serum & 32 & 0.003 & 0.020 & 0.044 & 0.13 & 0.11 & 1.2 \\
\hline$p, p^{\prime}-D D E$ Maternal serum & 32 & 0.24 & 0.57 & 0.78 & 2.0 & 1.3 & 25 \\
\hline$p, p^{\prime}-D D E$ Cord serum & 32 & 0.0050 & 0.12 & 0.22 & 0.52 & 0.48 & 4.0 \\
\hline$P C B 118$ Maternal serum & 32 & 0.0006 & 0.029 & 0.055 & 0.058 & 0.068 & 0.219 \\
\hline PCB 118 Cord serum & 32 & 0.0008 & 0.002 & 0.013 & 0.018 & 0.030 & 0.068 \\
\hline$P C B 138$ Maternal serum & 32 & 0.033 & 0.094 & 0.12 & 0.14 & 0.15 & 0.45 \\
\hline$P C B 138$ Cord serum & 32 & 0.0017 & 0.016 & 0.031 & 0.030 & 0.043 & 0.073 \\
\hline$P C B 153$ Maternal serum & 32 & 0.090 & 0.17 & 0.27 & 0.30 & 0.32 & 0.94 \\
\hline$P C B 153$ Cord serum & 32 & 0.023 & 0.037 & 0.057 & 0.064 & 0.084 & 0.16 \\
\hline PCB 180 Maternal serum & 32 & 0.040 & 0.14 & 0.20 & 0.22 & 0.25 & 0.61 \\
\hline$P C B 180$ Cord serum & 32 & 0.0052 & 0.027 & 0.041 & 0.043 & 0.051 & 0.11 \\
\hline PFOS Maternal serum & 38 & 0.062 & 1.9 & 2.9 & 3.2 & 3.9 & 13 \\
\hline PFOS Cord serum & 38 & 0.23 & 0.75 & 1.1 & 1.4 & 1.8 & 3.7 \\
\hline PFOA Maternal serum & 38 & 0.20 & 1.9 & 2.4 & 2.9 & 4.0 & 9.1 \\
\hline PFOA Cord serum & 38 & 0.17 & 0.29 & 1.6 & 1.6 & 2.2 & 5.0 \\
\hline
\end{tabular}

\subsection{Correlation Analyses}

For all analytes, data distributions were approximately log-normal. The Spearman non-parametric test was applied to all compounds, followed by a linear regression analysis performed on log-transformed data.

As shown in Table 3, a strong correlation was observed between concentrations in the maternal and the foetal compartment for PFOS (Spearman $r=0.74, \mathrm{p}<<0.001$ ), PFOA (Spearman $\mathrm{r}=0.70$, $\mathrm{p}<<0.001$ ), PCB 153 (Spearman $\mathrm{r}=0.60, \mathrm{p}<0.001$ ), HCB (Spearman $\mathrm{r}=0.68, \mathrm{p}<0.001$ ), PCB 180 (Spearman $\mathrm{r}=0.55, \mathrm{p}=0.0012$ ), and $p, p^{\prime}$-DDE (Spearman $\mathrm{r}=0.53, \mathrm{p}=0.0099$ ). A weak correlation $(\mathrm{p}<0.1)$ was observed for PCBs 118 and 138, and not significant correlation was found for $\beta-\mathrm{HCH}$. 
The regression analysis confirmed the results of the Spearman test and showed linear correlation between maternal and cord log-transformed concentrations for all the analytes with the exception of $\beta-\mathrm{HCH}, \mathrm{PCB} 118$ and PCB 138. With the exception of these latter compounds regression equations were calculated for all analytes. Intercepts and regression coefficients are reported in Table 3.

Table 3. Results from the Spearman and Pearson correlation analysis. Pearson regression was performed on $\log$ transformed data.

\begin{tabular}{|c|c|c|c|c|c|c|c|c|c|}
\hline $\begin{array}{l}\text { Cord serum vs. } \\
\text { maternal serum }\end{array}$ & $\begin{array}{c}\beta- \\
\text { HCH }\end{array}$ & HCB & $p, p$ '-DDE & PCB 118 & PCB 138 & PCB 153 & $\begin{array}{c}\text { PCB } \\
180 \\
\end{array}$ & PFOA & PFOS \\
\hline$N$ & 10 & 20 & 23 & 17 & 27 & 28 & 31 & 26 & 37 \\
\hline \multicolumn{10}{|l|}{$\begin{array}{l}\text { Spearman } \\
\text { correlation }\end{array}$} \\
\hline Coefficient (r) & 0.21 & $0.68 * * *$ & $0.53 * *$ & $0.45^{*}$ & $0.33 *$ & $0.60 * * *$ & $0.55 * *$ & $0.70 * * *$ & $0.74 * * *$ \\
\hline$p$ & 0.56 & 0.00088 & 0.0099 & 0.073 & 0.098 & 0.0007 & 0.0012 & $<<0.001$ & $<<0.001$ \\
\hline \multicolumn{10}{|l|}{ Pearson correlation } \\
\hline Coefficient (r) & 0.27 & $0.69 * * *$ & $0.55 * *$ & 0.3 & 0.29 & $0.57 * *$ & $0.51 * *$ & $0.75^{* * *}$ & $0.64 * * *$ \\
\hline$p$ & 0.44 & 0.0008 & 0.0064 & 0.24 & 0.14 & 0.0017 & 0.0034 & $<<0.001$ & $<<0.001$ \\
\hline Intercept & - & -0.353 & -0.45 & - & - & -0.881 & -0.973 & -0.033 & -0.298 \\
\hline $\begin{array}{l}\text { Regression } \\
\text { coefficient }\end{array}$ & - & 1.130 & 0.686 & - & - & 0.551 & 0.661 & 0.768 & 0.78 \\
\hline
\end{tabular}

$* \mathrm{p}<0.1 ; * * \mathrm{p}<0.05 ; * * * \mathrm{p}<0.001$

A significative $(p<0.05)$ correlation was found among the concentrations of all compounds, with the exception of PFOA, which correlates only with PFOS, and of PFOS, which does not correlate with PCB 118 and $p, p$ '-DDE.

No association could be observed for levels in maternal and cord blood, with birth weight and gestational age. However, a statistically significant correlation (Spearman test, $p<0.1$ ) was found between increasing levels of PCBs 118 (16 data) and 138 (22 data) in cord serum and decreasing Apgar score at $1 \mathrm{~min}$ (A1) and 5 min (A5) post-birth.

\section{Discussion and Conclusions}

Because of the importance of the fetal period with regard to development and differentiation, in utero exposure to POPs is of particular concern. Many of these compounds are in fact toxic for the immune, neurological, and endocrine systems, which experience critical developmental stages in the fetus. Transfer of toxic chemicals from maternal to fetal compartment across the placenta is similar to 
transfer across other biological membranes, and known to increase as the fetal growth rate increases [38].

This study addressed the partition of priority POPs between maternal and fetal serum, with the main objective to explore if a quantitative correlation could be defined to predict in utero exposure from maternal serum levels. To this aim, we enrolled a group of women from Rome, a city characterised by the absence of major industrial activities.

Concentrations of organochlorinated pollutants assessed in the group of women enrolled in the present study, expressed on a lipid basis for comparative purposes, are in agreement with those found in groups of women of the same age, determined by our group in studies conducted in the same years [39]. Levels of PFCs in maternal and cord serum observed in this study are generally lower than those found in other countries in the years 2004-2010 [26,28,40-43], and in agreement with levels detected in Germany and South Africa in the same period [44,45]. Our data confirm a comparatively low exposure of the Italian general population to PFCs, as we had already observed in a previous study [36].

The correlation analysis of measured POP concentrations shows that samples with comparatively higher levels of PCBs also have higher concentrations of organochlorinated pesticides, but not necessarily of PFOS and PFOA. This finding is not surprising because exposure to PCBs and organochlorinated pesticides occurs through the same routes (mainly diet, and primarily consumption of food of animal origin with high fat content), while exposure to PFOS and PFOA occurs via different routes. In fact, although food is considered the major intake pathway of PFCs in humans, release from food packaging products and inhalation of contaminated house dust may contribute a non-negligible fraction to the overall exposure [19].

As to the inverse correlation we observed between Apgar scores A1 and A5 and levels of PCB 118, this result is in line with what was observed by some authors in similar studies [50,51]. Nevertheless, because of the small number of data available for analysis, this finding can only be considered weakly indicative and therefore needs to be further investigated with a larger dataset.

Most of the POPs analysed were shown to cross the placental barrier, since they could be found in the fetal compartment, although the frequency of detection varied, ranging from $27 \%$ for $\beta$ - $\mathrm{HCH}$ to nearly $100 \%$ for PFOS and PCB 180, and to $100 \%$ of PFOA. Because all the analysed chemicals share common physical-chemical properties, it is very likely that, also for undetected compounds, a placental passage may occur, and they were not detected in cord serum samples only because of the small amount of cord sample $(<5 \mathrm{~mL})$ available. Analysis of the concentration ratios between the fetal and maternal compartments (Table 4) shows that the placental barrier partially only reduces the transport to the fetus and that some compounds, such as PFOA, and PCB 118 (and, to a lesser extent, PFOS, PCB 138 and $p, p$ '-DDE) may even concentrate in the fetal compartment. 
Table 4. POP ratios (\%) between concentrations in fetal and maternal compartments.

\begin{tabular}{ccccc}
\hline Compounds & N & Min & Mean & Max \\
\hline$\beta-\mathrm{HCH}$ & 10 & 2 & 18 & 54 \\
HCB & 20 & 5 & 39 & 100 \\
$p, p$ '-DDE & 23 & 5 & 40 & 106 \\
PCB 118 & 17 & 18 & 63 & 130 \\
PCB 138 & 27 & 6 & 33 & 114 \\
PCB 153 & 28 & 13 & 27 & 74 \\
PCB 180 & 31 & 4 & 21 & 40 \\
PFOS & 37 & 10 & 46 & 110 \\
PFOA & 26 & 17 & 87 & 177 \\
\hline
\end{tabular}

Although a straightforward comparison with results from other similar studies is hindered by a number of factors (such as the way to express concentrations, and the statistical approach) our results are consistent with findings obtained in another study carried out in Italy, in the polluted urban area of Brescia [46], which evidenced a linear correlation between levels of $p, p$ '-DDE, HCB, and total PCBs in maternal and cord serum, and with a study recently published by Needham et al. [47]. As to PFCs, our results confirm the good correlation between the maternal and the foetal compartment consistently observed for PFOS in published studies [44,47-49], while studies carried out on PFOA provide, on the whole, conflicting results [44,47-49].

The results of this study, to be considered preliminary because of the small number of samples analysed, show that, for a number of priority POPs (PFOS, PFOA, PCB 153, PCB 180, HCB and $p, p$ '-DDE), the placental transfer may be estimated through regression equations from concentrations assessed in maternal blood. A further investigation on a larger number of mother-newborn pairs would allow to better describe the quantitative relationships which characterize the transfer behaviour of priority POPs to the fetal compartment.

\section{Conflict of interest}

The authors have no commercial associations or sources of support that might pose a conflict of interest.

\section{References}

1. McGlynn, K.A.; Abnet, C.C.; Zhang, M.; Sun, X.D.; Fan, J.H.; O’Brien, T.R.; Wei, W.-Q.; Ortiz-Conde, B.A.; Dawsey, S.M.; Weber, J.-P.; et al. Serum concentrations of 1,1,1-trichloro2,2-bis(p-chlorophenyl)ethane (DDT) and 1,1-dichloro-2,2-bis(p-chlorophenyl)ethylene (DDE) and risk of primary liver cancer. J. Nat. Cancer Inst. 2006, 98, 1005-1010.

2. Pavuk, M.; Cerhan, J.R.; Lynch, C.F.; Kocan, A.; Petrik, J.; Chovancova, J. Case-control study of PCBs, other organochlorines and breast cancer in Eastern Slovakia. J. Expo. Anal. Environ. Epidemiol. 2003, 13, 267-275.

3. Cohn, B.A.; Terry, M.B.; Plumb, M.; Cirillo, P.M. Exposure to polychlorinated biphenyl (PCB) congeners measured shortly after giving birth and subsequent risk of maternal breast cancer before age 50. Breast Cancer Res. Treat. 2012, 136, 267-275. 
4. Recio-Vega, R.; Mendez-Henandez, A.; Padua Gabriel, A.; Jacobo-Avila, A.; Portales-Castanedo, A.; Hernandez-Gonzalez, S.; Gallegos-Arreola, M.P.; Ocampo-Gomeza, G. Potentially estrogenic polychlorinated biphenyls congeners serum levels and its relation with lung cancer. J. Appl. Toxicol. 2012, doi: 10.1002/jat.2763.

5. Freeman, M.D.; Kohles, S.S. Plasma levels of polychlorinated biphenyls, non-Hodgkin lymphoma, and causation. J. Environ. Public Health 2012, 2012, doi: 10.1155/2012/258981.

6. Schantz, S.L.; Gardiner, J.C.; Gasior, D.M.; Sweeney, A.M.; Humphrey, H.E.; McCaffrey, R.J. Motor function in aging Great Lakes fisheaters. Environ. Res. 1999, 80, S46-S56.

7. Schantz, S.L.; Gasior, D.M.; Polverejan, E.; McCaffrey, R.J.; Sweeney, A.M.; Humphrey, H.E.; Gardiner, J.C. Impairments of memory and learning in older adults exposed to polychlorinated biphenyls via consumption of Great Lakes fish. Environ. Health Perspect. 2001, 109, 605-611.

8. Ayotte, P.; Giroux, S.; Dewailly, É.; Hernandez, A.M.; Farias, P.; Danis, R.; Villanueva Díaz, C. DDT spraying for malaria control and reproductive function in Mexican men. Epidemiology 2001, 12, 366-367.

9. Dalvie, M.A.; Myers, J.E.; Thompson, M.L.; Robins, T.G.; Dyer, S.; Riebow, J.; Molekwa, J.; Jeebhay, M.; Millar, R.; Kruger, P. The long-term effects of DDT exposure on semen, fertility and sexual function of malaria vector control workers in Limpopo Province, South Africa. Environ. Res. 2004, 96, 1-8.

10. Martin, L.A. Differential effects of polychlorinated biphenyl (PCB) mixtures and congeners on the disposition of thyroxine(T4). Ph.D. Dissertation, Rutgers the State University of New Jersey, New Brunswick, NJ, USA, 2002.

11. Porpora, M.G.; Medda, E.; Abballe, A.; Bolli, S.; De Angelis, I.; di Domenico, A.; Ferro, A.; Ingelido, A.M.; Maggi, A.; Panici, P.B.; De Felip, E. Endometriosis and organochlorinated environmental pollutants: A case-control study on Italian women of reproductive age. Environ. Health Perspect. 2009, 117, 1070-1075.

12. Noakes, P.S.; Taylor, P.; Wilkinson, S.; Prescott, S.L. The relationship between persistent organic pollutants in maternal and neonatal tissues and immune responses to allergens: A novel exploratory study. Chemosphere 2006, 63, 1304-1311.

13. Schug, T.T.; Janesick, A.; Blumberg, B.; Heindel, J.J. Endocrine disrupting chemicals and disease susceptibility. J. Steroid Biochem. Mol. Biol. 2011, 127, 204-215.

14. OECD. Co-Operation on Existing Chemicals. Hazard Assessment of Perfluorooctane Sulfonate (PFOS) and its Salts. OECD (Organization for Economic Co-operation and Development): Paris, France, 2002, ENV/JM/RD 17/FINAL.

15. Kennedy, G.L.; Butenhoff, J.L.; Olsen, G.W.; O’Connor, J.C.; Seacat, A.M.; Perkins, R.G.; Biegel, L.B.; Murphy S.R.; Farrar, D.G. The toxicology of perfluorooctanoate. Crit. Rev. Toxicol. 2004, 34, 351-384.

16. US EPA. Draft Risk Assessment of the Potential Human Health Effects Associated with Exposure to Perfluorooctanoic Acid and its Salts. OPPT Review. Available online: http://www.epa.gov/oppt/pfoa/pubs/pfoarisk.pdf (accessed on 6 February 2013).

17. Lau, C.; Anitole, K.; Hodes, C.; Lai, D.; Pfahles-Hutchens, A.; Seed, J. Perfluoroalkyl acids: A review of monitoring and toxicological findings. Toxicol. Sci. 2007, 99, 366-394. 
18. Andersen, M.E.; Butenhoff, J.L.; Chang, S.C.; Farrar, D.G.; Kennedy, G.L.; Lau, C.; Olsen, G.W.; Seed, J.; Wallace, K.B. Perfluoroalkyl acids and related chemistries-Toxicokinetics and modes of action. Toxicol. Sci. 2008, 102, 3-14.

19. Benford, D.; de Boer, J.; Carere, A.; di Domenico, A.; Johansson, N.; Schrenk, D.; Schoeters, G.; de Voogt, P.; Dellatte, E. Scientific opinion of the panel on contaminants in the food chain of perfluorooctane sulfonate (PFOS), perfluorooctanoic acid (PFOA) and their salts. EFSA J. 2008, 653, 1-131.

20. Needham, L.; Calafat, A.; Barr, D. Uses and issues of biomonitoring. Int. J. Hyg. Environ. Health 2007, 210, 229-238.

21. Gilbert, M.E.; Rovet, J.; Chen, Z.; Koibuchi, N. Developmental thyroid hormone disruption: Prevalence, environmental contaminants and neurodevelopmental consequences. Neurotoxicology 2012, 33, 842-852.

22. Winneke, G. Developmental aspects of environmental neurotoxicology: Lessons from lead and polychlorinated biphenyls. J. Neurol. Sci. 2011, 308, 9-15.

23. Gray, K.A.; Klebanoff, M.A.; Brock, J.W.; Zhou, H.; Darden, R.; Needham, L.; Longnecker, M.P. In utero exposure to background levels of polychlorinated biphenyls and cognitive functioning among school-age children. Amer. J. Epidem. 2005, 162, 17-26.

24. Health Assessment Document for 2,3,7,8-Tetrachlorodibenzo-p-dioxin (TCDD) and Related Compounds (1994 Final Report). United States Environmental Protection Agency: Washington, DC, USA, 1994; EPA-600-BP-92-001 a-c.

25. Hertz-Picciotto, I.; Park, H.Y.; Dostal, M.; Kocan, A.; Trnovec, T.; Sram R. Prenatal exposures to persistent and non-persistent organic compounds and effects on immune system development. Basic Clin. Pharmacol. Toxicol. 2008, 102, 146-154.

26. Fei, C.; McLaughlin, J.K.; Lipworth, L.; Olsen, J. Maternal levels of perfluorinated chemicals and subfecundity. Hum. Reprod. 2009, 24, 1200-1205.

27. Joensen, U.N.; Bossi, R.; Leffers, H.; Jensen, A.A.; Skakkebæk, N.E.; Jørgensen, N. Do perfluoroalkyl compounds impair human semen quality? Environ. Health Perspect. 2009, 117, 923-927.

28. Washino, N.; Saijo, Y.; Sasaki, S.; Kato, S.; Ban, S.; Konishi, K.; Ito, R.; Nakata, A.; Iwasaki, Y.; Saito, K.; Nakazawa, H.; Kishi, R. Correlations between prenatal exposure to perfluorinated chemicals and reduced foetal growth. Environ. Health Perspect. 2009, 117, 660-667.

29. Nolan, L.A.; Nolan, J.M.; Shofer, F.S.; Rodway, N.V.; Emmett, E.A. The relationship between birth weight, gestational age and perfluorooctanoic acid (PFOA)-contaminated public drinking water. Reprod. Toxicol. 2009, 27, 231-238.

30. Grandjean, P.; Andersen, E.W.; Budtz-Jørgensen, E.; Nielsen, F.; Mølbak, K.; Weihe, P.; Heilmann C. Serum vaccine antibody concentrations in children exposed to perfluorinated compounds. JAMA 2012, 307, 391-397.

31. Huttont, E.K.; Hassan, E.S. Late vs. early clamping of the umbilical cord in full-term neonates: Systematic review and meta-analysis of controlled trials. JAMA 2007, 297, 1241-1252.

32. Bertino, E.; Spada, E.; Occhi, L.; Coscia, A.; Giuliani, F.; Gagliardi, L.; Gilli, C.; Fabris, C.; De Curtis, M.; Milani, S.; et al. Neonatal anthropometric charts: The Italian neonatal study compared with other European studies. J. Pediatr. Gastroenterol. Nutr. 2010, 51, 353-356. 
33. Ingelido, A.M.; Abballe, A.; Biagini, G.; di Domenico, A.; Marra, V.; Valentini, S.; De Felip, E. In-house validation of a time- and cost-saving method for the determination of indicator PCBs and organochlorinated pesticides in human serum. Organohalogen Compounds 2008, 70, 71-74.

34. Ingelido, A.M.; Abballe, A.; Marra, V.; Valentini, S.; Ferro, A.; Porpora, M.G.; Barbieri, P.G.; De Felip, E. Serum concentrations of beta-hexachlorocyclohexane in groups of the Italian general population: A human biomonitoring study. Ann. Ist. Super. Sanità 2009, 45, 401-408.

35. Porpora, M.G.; Medda, E.; Abballe, A.; Bolli, S.; De Angelis, I.; di Domenico, A.; Ferro, A.; Ingelido, A.M.; Maggi, A.; Benedetti Panici, P.; De Felip, E. Endometriosis and organochlorinated environmental pollutants: A case-control study on Italian women of reproductive age. Environ. Health Perspect. 2009, 117, 1070-1075.

36. Ingelido, A.M.; Marra, V.; Abballe, A.; Valentini, S.; Iacovella, N.; Barbieri, P.G.; Porpora, M.G.; di Domenico, A.; De Felip, E. Perfluorooctanesulfonate and perfluorooctanoic acid exposures of the Italian general population. Chemosphere 2010, 80, 1125-1130.

37. Rylander, L.; Nilsson-Ehle, P.; Hagmar, L. A simplified precise method for adjusting serum levels of persistent organohalogen pollutants to total serum lipids. Chemosphere 2006, 62, 333-336.

38. Murphy, V.; Smith, R.; Giles, W.; Clifton, V. Endocrine regulation of human fetal growth: The role of the mother, placenta, and fetus. Endocr Rev. 2006, 27, 141-169.

39. De Felip, E.; di Domenico, A. Studio epidemiologico sullo stato di salute e sui livelli d'accumulo di contaminanti organici persistenti nel sangue e nel latte materno in gruppi di popolazione a differente rischio d'esposizione nella Regione Campania. SEBIOREC Rapporto finale, December 2010.

40. Monroy, R.; Morrison, K.; Teo, K.; Atkinson, S.; Kubwabo, C.; Stewart, B.; Foster, W.G. Serum levels of perfluoroalkyl compounds in human maternal and umbilical cord blood samples. Environ. Res. 2008, 108, 56-62.

41. Fei, C.; McLaughlin, J.K.; Tarone, R.E.; Olsen, J. Perfluorinated chemicals and fetal growth: A study within the Danish national birth cohort. Environ. Health Perspect. 2007, 115, 1677-1682.

42. Fei, C.; McLaughlin, J.K.; Lipworth, L.; Olsen, J. Prenatal exposure to perfluorooctanoate (PFOA) and perfluorooctanesulfonate (PFOS) and maternally reported developmental milestones in infancy. Environ. Health Perspect. 2008, 116, 1391-1395.

43. Apelberg, B.J.; Witter, F.R.; Herbstman, J.B.; Calafat, A.M.; Halden, R.U.; Needham, L.L.; Goldman, L.R. Perfluorooctanoate (PFOA) in relation to weight and size at birth. Environ. Health Perspect. 2007, 115, 1670-1676.

44. Fromme, H.; Mosch, C.; Morovitz, M.; Alejandre, I.A.; Boehmer, S.; Kiranoglu, M.; Faber, F.; Hannibal, I.; Genzel-Boroviczény, O.; Koletzko, B.; Volkel, W. Pre- and postnatal exposure to perfluorinated compounds (PFCs). Environ. Sci. Technol. 2010, 44, 7123-7129.

45. Hanssen, L.; Röllin, H.; Odland, J.Ø.; Moeb, M.K.; Sandanger, T.M. Perfluorinated compounds in maternal serum and cord blood from selected areas of South Africa: Results of a pilot study. J. Environ. Monit. 2010, 12, 1355-1361.

46. Bergonzi, R.; Specchia, C.; Dinolfo, M.; Tomasi, C.; De Palma, G.; Frusca, T.; Apostoli, P. Distribution of persistent organochlorine pollutants in maternal and foetal tissues: Data from an Italian polluted urban area. Chemosphere 2009, 76, 747-754. 
47. Needham, L.; Grandjean, P.; Heinzow, B.; Jørgensen, P.; Nielsen, F.; Patterson, D.G., Jr.; Sjödin, A.; Turner, W.E.; Weihe, P. Partition of environmental chemicals between maternal and fetal blood and tissues. Environ. Sci. Technol. 2011, 45, 1121-1126.

48. Inoue, K.; Okada, F.; Ito, R.; Kato, S.; Sasaki, S.; Nakajima, S.; Uno, A.; Saijo, Y.; Sata, F.; Yoshimura, Y.; Kishi, R.; Nakazawa, H. PFOS and related perfluorinated compounds in human maternal and cord blood samples: Assessment of PFOS exposure in a susceptible population during pregnancy. Environ. Health Perspect. 2004, 112, 1204-1207.

49. Midasch, O.; Drexler, H.; Hart, N.; Beckmann, M.W.; Angerer, J. Transplacental exposure of neonates to perfluorooctanesulfonate and perfluorooctanoate: A pilot study. Int. Arch. Occup. Environ. Health 2007, 80, 643-648.

50. Tan, J.; Loganath, A.; Seng Chong, Y.; Obbard, J.P. Exposure to persistent organic pollutants in utero and related maternal characteristics on birth outcomes: A multivariate data analysis approach. Chemosphere 2009, 74, 428-433.

51. Wu, K.; Xu, X.; Liu, J.; Guo, Y.; Huo, X. In utero exposure to polychlorinated biphenyls and reduced neonatal physiological development from Guiyu, China. Ecotoxicol. Environ. Saf. 2011, $74,2141-2147$.

(C) 2013 by the authors; licensee MDPI, Basel, Switzerland. This article is an open access article distributed under the terms and conditions of the Creative Commons Attribution license (http://creativecommons.org/licenses/by/3.0/). 